\title{
Intrapulmonary airways visualized by staining and clearing of whole-lung sections: the transparent human lung
}

\author{
Hector Monforte-Muñoz and Rebekah L Walls \\ Division of Anatomic Pathology, Childrens Hospital Los Angeles, University of Southern California—Keck \\ School of Medicine, Los Angeles, CA, USA
}

\begin{abstract}
Methods for the study of cartilaginous airways represent technically very laborious and time-consuming procedures, many of these with the inevitable disruption or elimination of the distal bronchi and bronchioles. We describe and illustrate a methodology to demonstrate the cartilaginous support of the most distal intrapulmonary airways in hemisections or slabs of whole-, fixed-lung specimens. By this process, the cartilaginous framework of intrapulmonary air passages is highlighted and their outlines are defined. An important and distinct benefit of our procedure is the preservation of the alveolar parenchyma, vasculature and pleura, serving as an anatomic structural context. This improved methodology is based on procedures used in the past, now applied to entire half-sections or slabs of lungs, stained with toluidine blue, subsequent removal of stain from noncartilaginous elements and finally clearing of the specimen. The procedure takes 7-8 days but with limited technical - manual involvement. The resulting specimens demonstrate a highly complex, variable and at times, even unpredictable distribution of cartilage throughout the bronchial anatomy. This method represents a practical way of studying intact, this vital component of the respiratory tract. It also allows assessment of the potential implication of these critical smaller pathways in pathologic conditions, where thus far they have been under-studied.

Modern Pathology (2004) 17, 22-27, advance online publication, 5 December 2003; doi:10.1038/modpathol.3800003
\end{abstract}

Keywords: bronchial anatomy; bronchial cartilage pathology; pulmonary structural anatomy

The lord God formed the man from the dust of the ground and breathed into his nostrils the breath of life, and the man became a living being. Genesis 2:7

The study of the gross structural characteristics of the airways has been the subject of detailed and meticulous analysis. Over the past 60 years, various landmark publications focusing on their cartilaginous framework have been published. ${ }^{1-8}$ These studies have used gross dissection, serial section reconstruction and or staining/clearing methods, most of them necessarily examining only the trachea and the most proximal bronchial generations. Many of these procedures have cumbersome specimen preparation requirements and prolonged procedural times. The highly detailed

Correspondence: H Monforte-Muñoz, Department of Pathology, CHLA Box 43, 4650 Sunset Blvd, Los Angeles, CA, 90027, USA. E-mail: hmonforte@chla.usc.edu

Presented in part at the USCAP meeting of the Society for Pediatric Pathology, March 22, 2003. Washington, D.C.

Received 13 June 2003; revised 29 July 2003; accepted 10 September 2003; published online 5 December 2003 contributions of Miller and of Hayward and Reid are still the main references in the descriptions and study of intrapulmonary bronchial cartilage anatomy. ${ }^{1,4,7,8}$

We have adapted a method used in the past for tracheo-bronchial tree staining, ${ }^{5,6,9}$ developed and utilized it to visualize the intrapulmonary airways in-situ, with the benefit of preservation of the supporting alveolar parenchyma, pulmonary vasculature and pleura, all these serving as structural and topographic references.

We are unaware of any written or illustrated documentation of this methodology in the English literature.

\section{Materials and methods}

Lung Specimens

Eight lungs were selected from the tissue archives in the division of anatomic pathology from our institution (Table 1).

The specimens selected for study had been initially cut in a suitable plane and consisted of 
Table 1 Summary of specimens used

\begin{tabular}{|c|c|c|c|c|}
\hline $\begin{array}{l}\text { Patient }[X] \\
\text { Figure\# }\end{array}$ & Age & $\begin{array}{l}\text { Specimen studied/plane } \\
\text { of lung cut }\end{array}$ & Pulmonary alterations & Main disease(s) \\
\hline $\begin{array}{l}{[\mathrm{A}]} \\
2\end{array}$ & 20 years & $\begin{array}{l}\text { Lt. lower lobe - slab } \\
\text { Coronal }\end{array}$ & Pulmonary hypertension - V & Pulmonary hypertension \\
\hline $\begin{array}{l}{[\mathrm{B}]} \\
1 \mathrm{~b} / 3 \mathrm{a}\end{array}$ & 15 years & $\begin{array}{l}\text { Lt. lower lobe - slab } \\
\text { Coronal }\end{array}$ & Congestion & Mediastinal lymphoma \\
\hline $\begin{array}{l}{[\mathrm{C}]} \\
3 \mathrm{~b}\end{array}$ & 13 years & $\begin{array}{l}\text { Lt. upper lobe- slab } \\
\text { Coronal }\end{array}$ & Patchy pneumonia & Disseminated neuroblastoma \\
\hline $\begin{array}{l}{[\mathrm{D}]} \\
1 \mathrm{a} / 1 \mathrm{c}\end{array}$ & 7 years & $\begin{array}{l}\text { Lt. lower lobe - slab } \\
\text { Coronal }\end{array}$ & Pulmonary hypertension - I & $\begin{array}{l}\text { Pulmonary hypertension } \\
\text { Hemorrhage }\end{array}$ \\
\hline $\begin{array}{l}{[\mathrm{E}]} \\
4 \mathrm{a}\end{array}$ & 11 months & $\begin{array}{l}\text { Rt. lung slab } \\
\text { Coronal }\end{array}$ & Bronchopneumonia early & Cirrhosis, coagulopathy \\
\hline $\begin{array}{l}{[\mathrm{F}]} \\
4 \mathrm{~b}\end{array}$ & 3 months $^{\mathrm{a}}$ & $\begin{array}{l}\text { Rt. lung slab } \\
\text { Coronal }\end{array}$ & CMV pneumonia & $\begin{array}{l}\text { Premie } 28 \text { weeks, IDM, brain hemorrhage, } \\
\text { myopathy }\end{array}$ \\
\hline $\begin{array}{l}{[\mathrm{G}]} \\
4 \mathrm{C}\end{array}$ & 8 weeks & $\begin{array}{l}\text { Rt. lung - unilobar - slab } \\
\text { Parasagital }\end{array}$ & $\begin{array}{l}\text { Alveolar capillary dysplasia } \\
\text { Pulmonary hypertension }\end{array}$ & $\begin{array}{l}\text { Pulmonary hypertension } \\
\text { Alveolar capillary dysplasia }\end{array}$ \\
\hline $\begin{array}{l}{[\mathrm{H}]} \\
4 \mathrm{~d}\end{array}$ & 4 weeks & $\begin{array}{l}\text { Lt. lower lobe }-1 / 2 \\
\text { Coronal }\end{array}$ & Congestion & $\begin{array}{l}\text { Congenital heart disease } \\
\text { Hypoplastic left heart }\end{array}$ \\
\hline
\end{tabular}

${ }^{\mathrm{a}}$ Corrected age $=2$ weeks post-term. $\mathrm{IDM}=$ maternal diabetes.

light, crepitant lungs devoid of any significant infiltrative process or cellular consolidation; hemorrhagic lungs without areas of induration or infarction were also used.

\section{Lung Preparation, Staining and Clearing (Transparent Lung) Method}

(1) All lungs had been fixed by perfusion via the trachea or main bronchus with buffered $10 \%$ formalin solution.

(2) Whole specimens should be sectioned along the coronal plane, just anterior and posterior to the main bronchus, obtaining a $1 \mathrm{~cm}$ thick slab of a lobe or the whole lung. The smaller lungs should be bisected and the posterior half used for the procedure.

(3) All tissues should be fixed for at least $24 \mathrm{~h}$.

(4) Immerse the slabs into commercially available, $3 \% \mathrm{H}_{2} \mathrm{O}_{2}$. This should be in approximately 10 times the lung volume.

(5) Leave the specimens in this solution for at least $36-48 \mathrm{~h}$, under continuous rotating motion, using a variable rotator at $70 \mathrm{rpm}$. This allows all red blood cells in capillaries and alveoli to hemolyze. At that time, the parenchyma should become tan-white throughout (Figure 1a).

(6) Rinse the specimens in various changes of distilled water and immerse them in $70 \%$ ETOH for $6 \mathrm{~h}$.

(7) Stain the lung tissue for 24-36h (depending on size) using continuous rotating motion, in a solution of $0.25 \%$ toluidine blue in $70 \%$ ethanol at $\mathrm{pH} 2$, adjusted with $\mathrm{HCl}$.

(8) For initial decolorization, rinse the specimens in running, warm tap water with gentle manipulation of the lung to eliminate the excess stain.

(9) For gradual decolorization of the spongy parenchyma and connective tissue, immerse specimens in various changes of 70\% ETOH in a closed, double-bottom chamber, using a magnetic stirrer at a slow setting, under $2 \mathrm{mmHg}$ of vacuum.

(10) The $70 \%$ ethanol should be changed multiple times to allow the stain to be entirely removed. In larger specimens, small incisions into the pleural surface might have to be made to expedite this process, which lasts 3-5 days.

(11) For removal of the stain and enhanced ultimate transparency, we found it helpful to place the specimens in a solution of acid-alcohol $(10 \%$ acetic acid/70\% ETOH overnight or 1\% HCL/ $70 \%$ ETOH for periods ranging between 1 and $4 \mathrm{~h}$ ) towards the end of the procedure.

(12) Decolorization is considered sufficient or optimal when the lung parenchyma showed only a faint blue tinge (Figure 1b).

(13) It is important not to allow any of the darkly stained cartilage (visible either in the hilus region or on the surface) to lose its dark-blue saturation during this process. This serves as a built-in control.

(14) The specimens are then further dehydrated by placing them into increasing (80, 95 and $100 \%$ ) concentrations of ETOH for $3 \mathrm{~h}$ in each solution under continuous motion utilizing the same vacuum conditions.

(15) Once dehydrated, clear the tissues in three changes of histology-grade xylene, each lasting $2 \mathrm{~h}$.

(16) Lastly, completely clear the specimens by placing them into methyl salicylate solution (ICN Biomedicals, Inc. Cat. No. 155657, Aurora, 
$\mathrm{OH}, \mathrm{USA}$ ) at room temperature for at least $24 \mathrm{~h}$. Longer storage in this solution will improve the transparency and the end result.
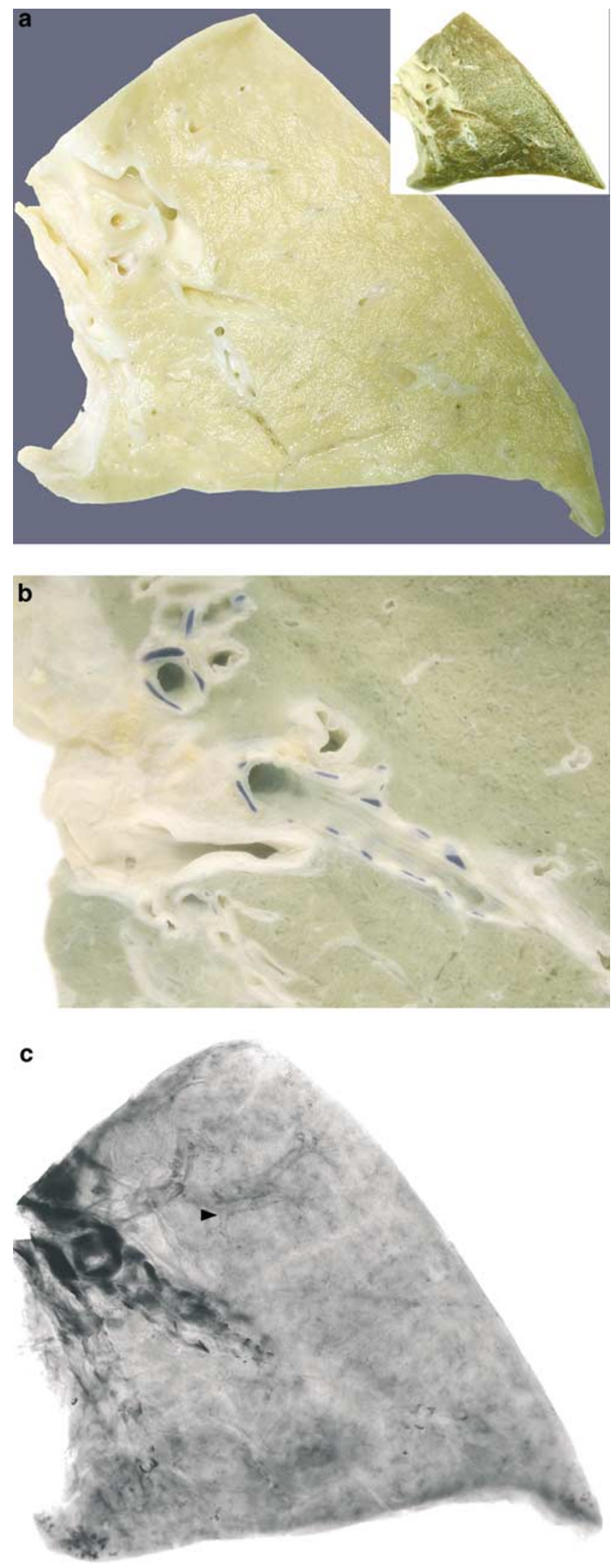

Photographs were taken at least 2 days after completion (Figure 1c).

\section{Photographic Imaging and Illustration}

For illustration purposes, we trans-illuminated the specimens by using a fluorescent lamp (total $200 \mathrm{~W}$ ) background under white translucent Plexiglass ${ }^{\mathrm{TM}}$ Digital images were taken with a Nikon Coolpix 990-3.4. megapixel digital camera, set at aperture priority. These images were downloaded into Adobe ${ }^{\mathbb{R}}$ Photoshop ${ }^{\circledR}$ v 6.0 (Adobe Systems Incorporated, San Jose, CA, USA) and adjusted for optimum clarity and true color using Photoshop's 'levels' and 'color balance' controls. Some were also converted to grayscale images.

\section{Results and findings}

We were able to successfully visualize the intrapulmonary bronchial anatomy and cartilaginous structure distribution present in all specimens submitted for staining. From the variable results of parenchymal color and transparency, we determined that the critical steps in our procedure are: (a) hemolysis by hydrogen peroxide and (b) the gradual decolorization of the specimens.

Insufficient hemolysis results in a strong dark amber color or residual opaque brown pools of blood in the final cleared specimen, and/or inability to decolorize satisfactorily; this was resolved by reprocessing the specimen back to $70 \% \mathrm{ETOH}$ and then re-hemolyzing in $\mathrm{H}_{2} \mathrm{O}_{2}$ for at least $24 \mathrm{~h}$.

Inadequate decolorization results in a dark greenblue translucent parenchyma; conversely, a very rapid decolorization, particularly using higher acid concentrations or longer exposure to them, results in inevitable fading of the stain within the cartilaginous structures, decreasing their desirable contrast.

The major disadvantage of our procedure is the fact that there is a limit in lung thickness, no greater than $1.5 \mathrm{~cm}$, beyond which the lung parenchyma cannot be made clear enough to allow satisfactory visualization of the airways. When the whole bronchial tree is to be studied, careful planning by isolation of lung segments or preparation of serial slabs should overcome this limitation. The actual appearance of the specimens is more dramatic than what is apparent in some of our illustrations.

Figure 1 (a) Composite view of lung specimen [D] $\times$ after $\mathrm{H}_{2} \mathrm{O}_{2}$ step, showing complete removal of any red blood cell components from the parenchyma. Inset (upper right) shows original formalinfixed specimen. (b) Acceptable residual parenchymal faint hue of toluidine blue staining after decolorization procedure, showing dark-blue stain affinity of superficially apparent cartilaginous bronchial structures (specimen [B]). (c) Cleared lung after immersion in methyl salicylate; axial pathway and lateral (arrowhead) 'wide-angle' branches showing limited cartilaginous support. 


\section{Discussion}

Techniques for gross demonstration and staining of cartilage and bony skeleton have been used for many years. ${ }^{10-12}$ The specific application of these techniques to the upper and lower airways was suggested by Moreira da Rocha in $1917^{13}$ and appears utilized and illustrated for the first time in various, more recent publications. ${ }^{5,6,9,14}$ The gross and microscopic study of the intrapulmonary bronchial cartilaginous support has been the subject of interesting studies, both of the normal anatomy and pathologic conditions. ${ }^{3-5,7-9,14-19}$

Our findings confirm previously documented characteristics of the pulmonary bronchial tree regarding the irregular branching patterns and the variability of their cartilaginous support. ${ }^{4,7,8}$ As described in those publications, the most proximal intrapulmonary bronchial cartilaginous support is not only by isolated cartilaginous formations but also may consist of a mesh-like cartilaginous sleeve (Figure 2). Individual cartilage structures are complex-shaped formations as opposed to regular plates and their distribution distally is that of very irregularly widely spaced structures, some at the mouth of emerging lateral bronchial branches, some at points of acute angle bifurcation and others within the length of the airway, extending to within a few generations of the pleural surface (Figure 3a,b). The axial pathways certainly have continuous cartilaginous support in several generations, but many of the generations referred to as 'wide angle'

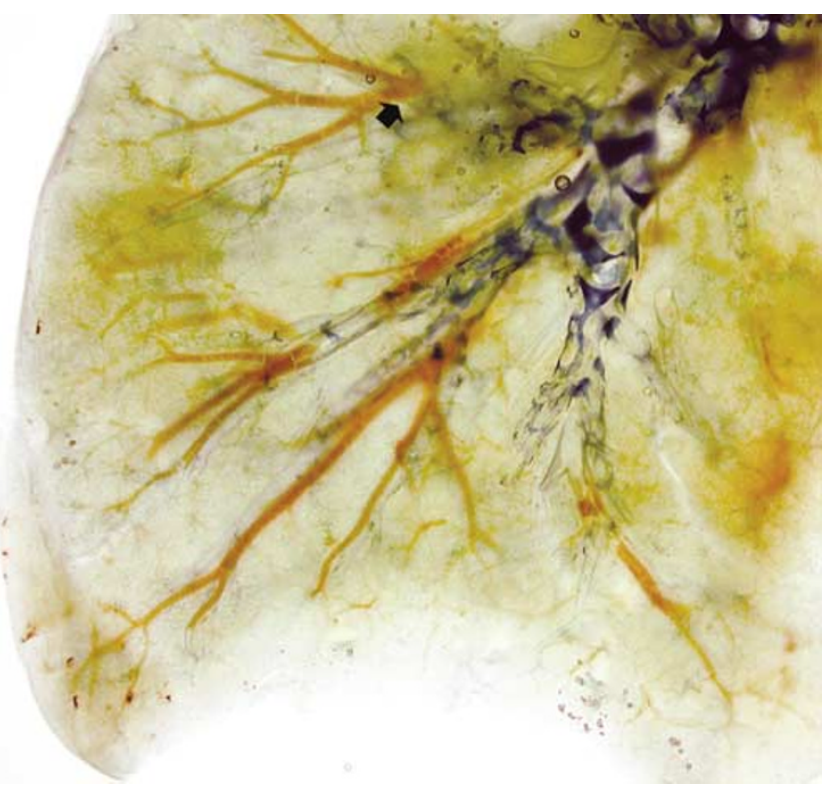

Figure 2 Specimen [A]. Apparent main-stem intermediate bronchi and various segmental and sub-segmental bronchi with their entire branching pattern, the wide-angle branch (arrow) devoid of cartilaginous support shortly after its origin; a serendipitous feature is the preservation in some cases of residual blood in branches of the pulmonary artery serving as contrastenhancing reference structures.
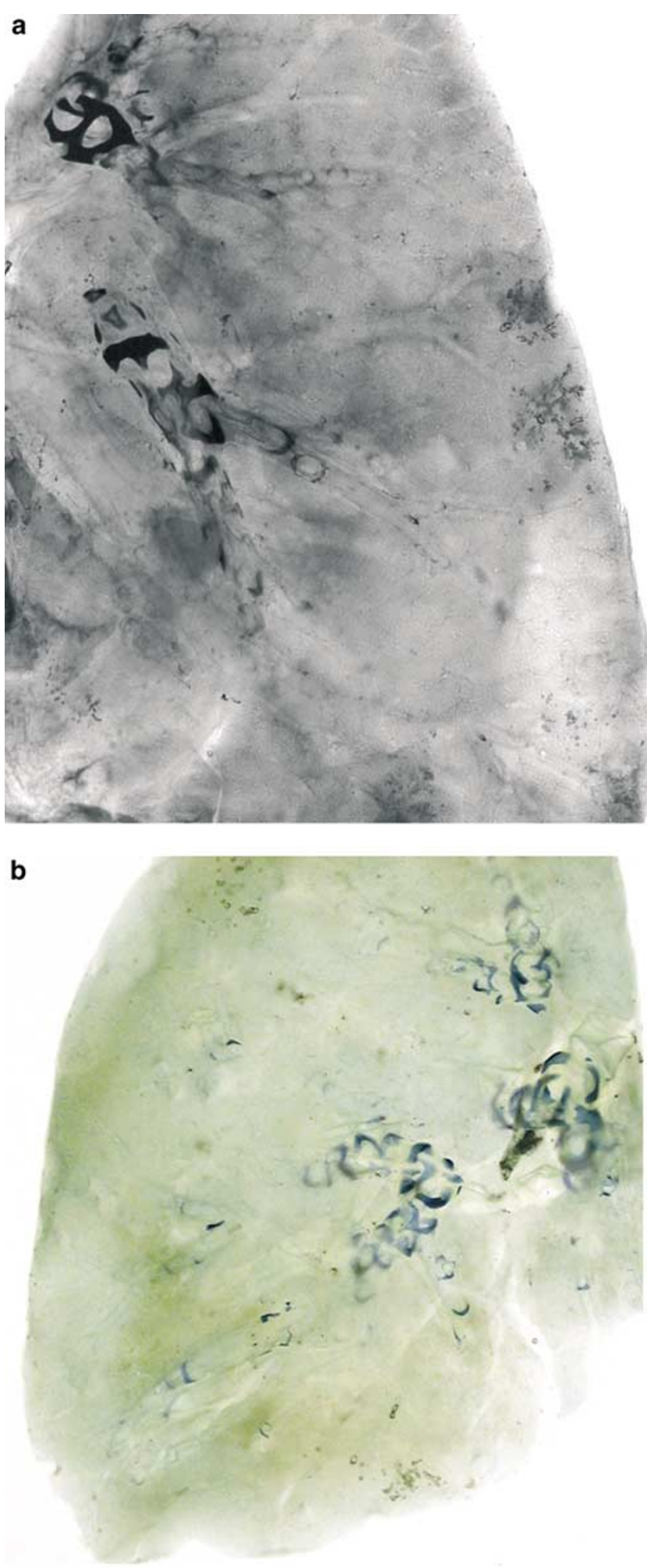

Figure 3 (a,b) Illustration of specimens [B,C], respectively, showing increase in individual size of cartilaginous formations when compared to infant's lungs (see below). Most of the subsegmental generations show cartilaginous structures at branching points, but some ring-like formations along their length. 
26
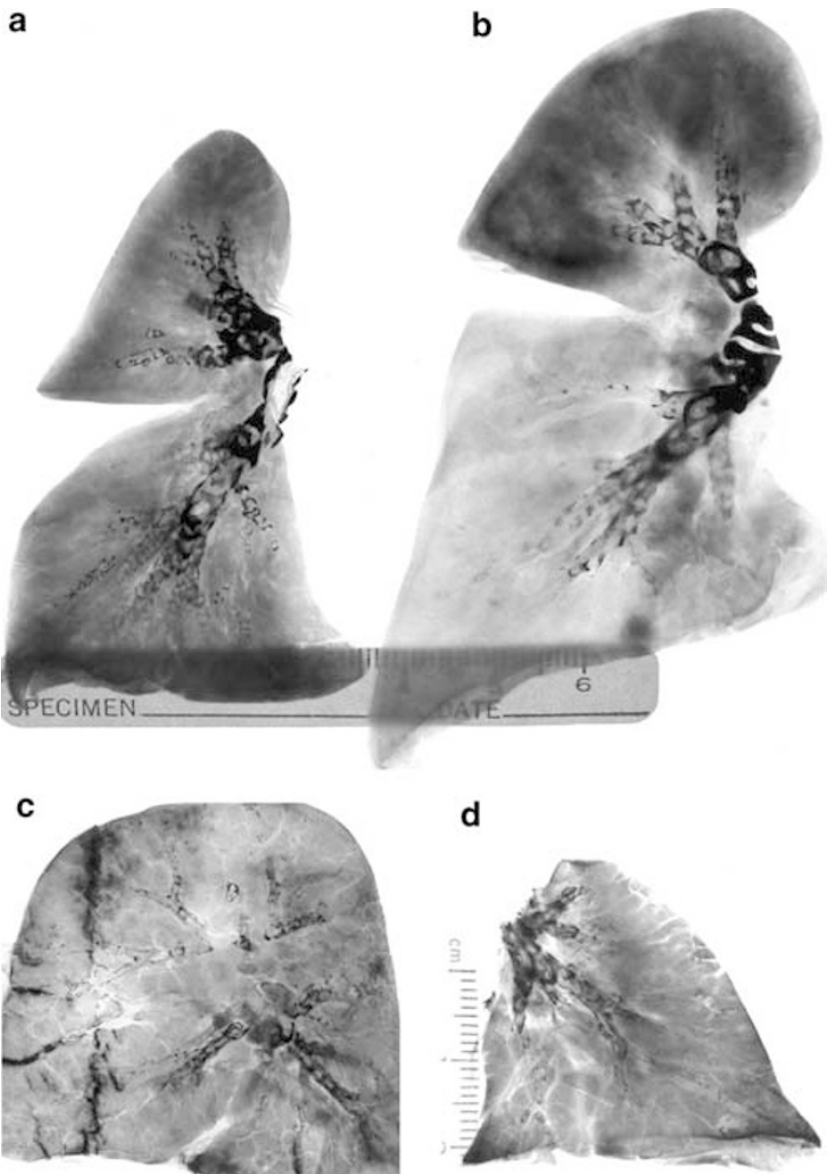

d

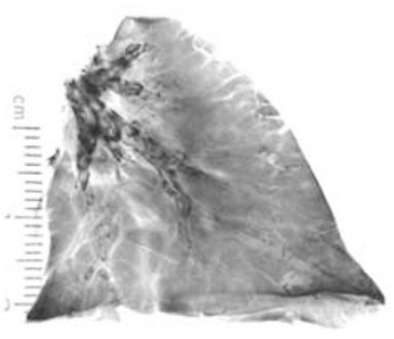

Figure 4 (a-d) Lungs $[\mathrm{E}-\mathrm{H}]$, respectively. The number of recognizable cartilaginous formations and patterns appears established prior to birth, in infant's lungs they appear as a continuous mesh in some bronchi. Although a unilobar lung. (c) shows parasagittal cut of the lung, the distal cartilaginous framework appears to be normally developed in alveolar capillary dysplasia. Specimen $[\mathrm{H}]$ in (d) is the posterior half of the left lower lobe showing limited cartilaginous development when compared to specimens from slightly older lungs [E-G].

are entirely devoid of cartilage (Figures 2 and 3 ). This variability suggests that there is a unique pattern of cartilaginous infrastructure, selective development and increase in the size of cartilage formations as the bronchi elongate and the alveolated lung continues to grow, expand and specialize during infancy and childhood; the number of cartilaginous structures is already established at birth $^{4}$ (Figure 4a-d).

Visualization of the intrapulmonary airways enables a rapid assessment of airway stability in conditions where this may be in question; it also permits the potential of finding bronchial wall support deficiencies in many unsuspected disease states. This was beautifully illustrated by Stovin in 1959 and by Campbell 10 years later, in their dissected airways studies of 'congenital lobar emphysema'.9,14 For additional studies in human embryos or very small animals, whole lungs may be used, as shown by Vanpeperstraete in 1973 and

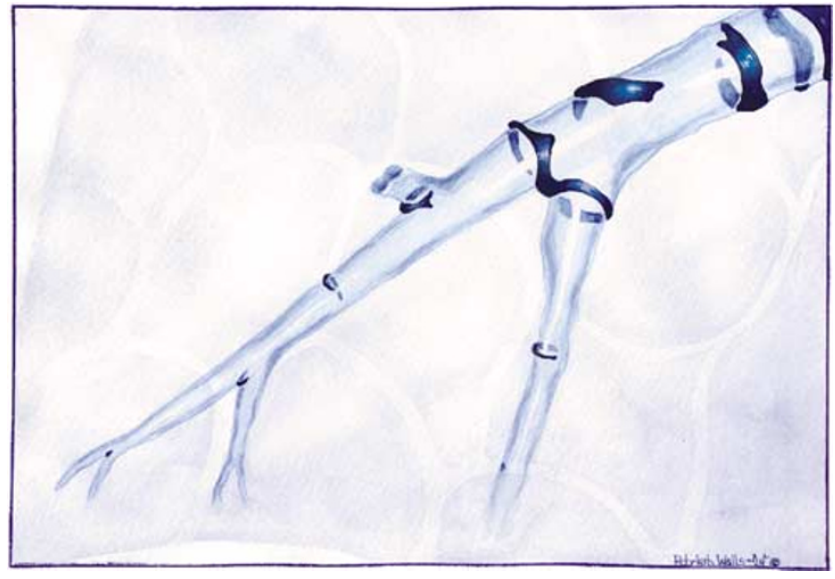

Figure 5 Artistic rendition of bronchial cartilaginous support in distal airways; the completely isolated and remote islands of cartilage in very distal bronchial generations suggest that they remained in place and became modified as the bronchus pathway elongated during development; their residual placement also suggests a role in respiratory dynamics.

Valerius in 1998 without major difficulty, and by using our methodology, avoiding the need for maceration and loss of structural detail. ${ }^{6,18}$ For the study of larger lungs then the use of whole-lung slabs is preferable.

In conclusion, the variability of cartilage configuration in proximal segmental airways, the presence of isolated cartilage formations in very distal air passages and the variable spectrum of cartilaginousformation density and configuration between pulmonary lobes and segments appear to be distinctive characteristics of the human lung (Figure 5). ${ }^{18}$ The role that the intrapulmonary cartilage infrastructure serves in airway and respiratory dynamics and their disease states remain to be explored further. ${ }^{1,18,19}$

\section{Acknowledgements}

We acknowledge the expert assistance of Ms Sue Ann Phung, HTL (ASCP).

\section{References}

1 Miller WS. The Lung, 2nd ed, Charles C. Thomas: Springfield IL, 1947.

2 Reid L. Visceral cartilage. J Anat 1976;122:349-355.

3 Sinclair-Smith CC, Emery JL, Gadsdon D, Dinsdale F, Baddeley J. Cartilage in children's lungs: a quantitative assessment using the right middle lobe. Thorax 1976;31:40-43.

4 Bucher U, Reid L. Development of the intrasegmental bronchial tree: the pattern of branching and development of cartilage at various stages of intra-uterine life. Thorax 1961;16:207-218.

5 Landing BH, Wells TR. Tracheobronchial anomalies in children. In: Rosenberg HS, Bolande RP (eds). Pers Ped Pathol, Vol. 1. Year Book Medical Publishers, Inc.: Chicago, IL, 1973; pp 1-32. 
6 Vanpeperstraete F. The cartilaginous skeleton of the bronchial tree. Adv Anat Embryol Cell Biol 1973;48: 1-80.

7 Hayward J, Reid L. The cartilage of the intrapulmonary bronchi in normal lungs, in bronchiectasis, and in massive collapse. Thorax 1952;7:98-110.

8 Hayward J, Reid L. Observations on the anatomy of the intrasegmental bronchial tree. Thorax 1952;7:89-97.

9 Stovin PGI. Congenital lobar emphysema. Thorax 1959;14:254-262.

10 Shulze P. Ueber herstellung und conservierung durchsichtiger embryonen zum studium der skeletbildung. Anat Anz 1897;13:3-5.

11 Wijhe Jv. A New Method of Demonstrating cartilaginous Microskeletons. Verh. K. Akad. Wetensch: Amsterdam, Netherlands, 1902.

12 Miller C. Demonstration of the cartilaginous skeleton in mammalian fetuses. Anat Rec 1921;20:415-419.

13 Moreira Da Rocha J. Staining of adult cartilage by Lundwall's methods. Anat Rec 1917;13:447-449.
14 Campbell PE. Congenital lobar emphysema. Aust Ped J 1969;5:226-233.

15 Johnson JE, Perkett EA, Meyrick B. Pulmonary veins and bronchial vessels undergo remodeling in sustained pulmonary hypertension induced by continuous air embolization into sheep. Exp Lung Res 1997;23:459-473.

16 Monforte-Munoz H. Acquired degeneration and paucity of intrapulmonary bronchial cartilage. Paper presented at USCAP Pediatric Pathology Specialty Conference. San Francisco, CA, 1999.

17 Sedivy R, Bankl HC, Stimpfl T, Bankl H, Kurkciyan I. Sudden, unexpected death of a young marathon runner as a result of bronchial malformation. Mod Pathol 1997;10:247-251.

18 Valerius KP. Size-independent distribution of bronchial cartilage in four species of myomorph rodents. Int J Mamm Biol 1998;63:220-227.

19 Hale FC, Olsen CR, Mickey MR. The measurement of bronchial wall components. Am Rev Resp Dis 1968;98:978-987. 